\title{
Progressive Collapse of Structures
}


Downloaded by [] on [26/04/23]. Copyright @ ICE Publishing, all rights reserved. 


\section{Progressive Collapse of Structures}

\section{Second edition}

\section{Uwe Starossek}

Dr-Ing, PE

Professor of Structural Engineering Hamburg University of Technology

Hamburg, Germany 
Published by ICE Publishing, One Great George Street, Westminster, London SW1P 3AA.

Full details of ICE Publishing representatives and distributors can be found at: www.icebookshop.com/bookshop_contact.asp

\section{Other titles by ICE Publishing:}

Blast Effects on Buildings, Second edition.

D. Cormie et al. ISBN 978-0-7277-3521-8

Modern Structural Analysis: Modelling Process and Guidance.

I. A. MacLeod. ISBN 978-0-7277-3279-8

Conceptual Structural Design, Second edition.

O. Larsen. ISBN 978-0-7277-6110-1

www.icebookshop.com

A catalogue record for this book is available from the British Library

ISBN 978-0-7277-6168-2

(c) Thomas Telford Limited 2018

ICE Publishing is a division of Thomas Telford Ltd, a wholly-owned subsidiary of the Institution of Civil Engineers (ICE).

All rights, including translation, reserved. Except as permitted by the Copyright, Designs and Patents Act 1988, no part of this publication may be reproduced, stored in a retrieval system or transmitted in any form or by any means, electronic, mechanical, photocopying or otherwise, without the prior written permission of the Publisher, ICE Publishing, One Great George Street, Westminster, London SW1P 3AA.

This book is published on the understanding that the author is solely responsible for the statements made and opinions expressed in it and that its publication does not necessarily imply that such statements and/or opinions are or reflect the views or opinions of the publishers. While every effort has been made to ensure that the statements made and the opinions expressed in this publication provide a safe and accurate guide, no liability or responsibility can be accepted in this respect by the author or publishers.

While every reasonable effort has been undertaken by the author and the publisher to acknowledge copyright on material reproduced, if there has been an oversight please contact the publisher and we will endeavour to correct this upon a reprint.

Commissioning Editor: Laura Balchin Development Editor: Maria Inês Pinheiro Production Editor: Madhubanti Bhattacharyya Market Development Executive: Elizabeth Hobson

Typeset by C\&M Digitals (P) Ltd, Chennai, India Index created by Nigel d'Auvergne Printed and bound in Great Britain by TJ International, Padstow 
To the memory of my father Rudolf Starossek 
Downloaded by [] on [26/04/23]. Copyright @ ICE Publishing, all rights reserved. 


\section{Contents}

Foreword

Preface

xi

Preface to the first edition xiii

About the author

01

Introduction

1.1. Opening

1.2. Failure incidents

1.3. State of research

1.4. Standards and guidelines

References

02

Typology of progressive collapse

2.1. General 18

2.2. Types of progressive collapse 18

2.3. Classes of progressive collapse 34

2.4. Collapse-promoting features 35

2.5. Summary 39

References $\quad 40$

03

Ordinary design procedures

3.1. Inadequacy of ordinary procedures 43

3.2. Possible improvements 45

References $\quad 46$

04

Design against disproportionate collapse

4.1. General

4.2. Two definitions

4.3. Design criteria

References

05

Design methods

5.1. General

5.2. Prevent local failure 63

5.3. Assume local failure 66

5.4. Local failure: prevent or assume? 85

5.5. Prescriptive design rules 87

References $\quad 89$

06

Applications

6.1. General 91

6.2. Design of collapse-resistant bridges 91

6.3. Design of collapse-resistant high-rise buildings 102 References

07

Measures of robustness and collapse resistance

7.1. General

7.2. Areas of application 
7.3. Requirements 130

7.4. Present approaches 130

7.5. Damage-based measures of robustness 131

7.6. Stiffness-based measures of robustness 134

7.7. Reserve-based measures of robustness 135

7.8. Energy-based measures of robustness $\quad 137$

7.9. Conclusions and future directions 138

References 139

08

Model guidelines $\quad 141$

8.1. General 141

8.2. Scope 141

8.3. Definitions 142

8.4. Design criteria 150

8.5. Design requirements 152

8.6. Design objectives 155

8.7. Design methods 159

8.8. Verification procedures 164

8.9. Documentation 165

References 165

09

Current codification $\quad 167$

9.1. General 167

9.2. Unified Facilities Criteria (UFC) 167

9.3. General Services Administration
(GSA) guidelines

9.4. Eurocode EN 1991-1-7 184

9.5. ASCE guidance documents 190

9.6. Summary 192

References 193

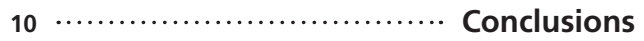

10.1. Synopsis 195

10.2. Outlook 198

$\begin{array}{ll}\text { Index } & 201\end{array}$

viii 


\section{Foreword}

Structural collapses are common occurrences worldwide. These extreme events afflict a wide range of structural systems and materials, and are initiated by a variety of causes. While most collapses occur with little notice or fanfare, a few are prominently reported in the news. Those that occur during construction are typically attributed to contractor error or design flaw, while others that occur after years of useful service are often attributed to extreme abnormal events. The gamut is expansive and there may seemingly be no common thread other than the resulting destruction, injuries, cost to reconstruct and interruption of function, particularly when the collapse is widespread and/ or sudden. However, we can distinguish between events that produce global damage and events that cause local damage that subsequently propagates into a disproportionately larger collapse.

Over the years, advances in computational methods have allowed engineers to optimise the design of structures to satisfy code requirements. These designs provide acceptable performance in response to gravity loads, extreme wind pressures and seismic excitation, and the building codes are continually updating their requirements to permit innovation and cost reduction while maintaining public safety. These designs also perform reasonably well in response to fire, through the specification of resistive materials and sprinklers. Although many building codes and regulations explicitly address the prevention of structural collapse in response to unexpected or abnormal circumstances, some codes only obliquely address this subject. Furthermore, an ongoing debate questions the premise upon which structures might be designed to resist very low probability but very high consequence events. As a result, current code requirements for structural integrity include some combination of prescriptive detailing for continuity and notional accidental loads, enhanced robustness and bridging over the removal of key elements.

Uwe Starossek's first edition of Progressive Collapse of Structures was impressive; however, the second edition so much more comprehensively covers its subject. It systematically catalogues the typology of progressive collapse, which helps the reader understand the phenomenon as it applies to different structural systems and the limitations of building code design to provide effective 
resistance to the progression of collapse. The book also introduces the reader to various design strategies to arrest the progression of collapse, applications to a variety of structural systems, model guidelines and current codification. Most significantly, this book will help engineers enhance public safety while considering the corresponding cost, space and constructability implications for new construction and the renovation of existing buildings.

Robert Smilowitz Senior Principal Thornton Tomasetti 


\section{Preface}

With the need for a second edition came the opportunity to thoroughly revise and extend this book on progressive and disproportionate collapse. Many new publications are taken into account and new insights of my own are incorporated here. Moreover, two new chapters are added. One of them gives an outline, interpretation and evaluation of current US and European codification for the design of structures against disproportionate collapse. The other new chapter offers model guidelines that can be used as a basis for project-specific design criteria or can serve as a model for regulations. In contrast to current codification, the model guidelines are not limited to building design but apply to all kinds of structures.

It is hoped that with this new material the book is fairly comprehensive and complete. The chapters are intended to integrate well and to form a cohesive whole. Nevertheless, selected chapters can be read individually, depending on the interest of the reader. The selective reader will appreciate, I hope, the strong cross-referencing throughout the book and the index.

Thanks are due to Robert Smilowitz, Mark Waggoner, Karl Rubenacker and my former student Marco Haberland for their input to an ASCE sub-committee draft that formed the basis of the model guidelines offered here. The new chapter on current codification strongly benefited from discussions I had with my student Richard Terrill. He also read the entire second edition manuscript and made many good suggestions that helped to improve clarity and correctness. All this is highly appreciated.

I would like to thank my student Nikolay Lalkovski for our discussions on pancake-type collapse and his input into Chapter 6. Furthermore, I would like to gratefully mention my former student Julia Kempski for her remarks on structural irregularity, Axel Seils for creating the drawings and Inge Spahn for taking care of media usage rights acquisition and office management.

Finally, it is my pleasure to acknowledge the enthusiastic and competent support from the editors at ICE Publishing, Laura Balchin, Inês Pinheiro and Madhubanti Bhattacharyya.

Uwe Starossek 
Downloaded by [] on [26/04/23]. Copyright @ ICE Publishing, all rights reserved. 


\section{Preface to the first edition}

I became involved with the topic of this book 16 years ago when, as a practising engineer involved in the design of the Confederation Bridge, Canada, I was charged with the progressive collapse analysis and design of that structure. Apart from a few papers, mostly on the Ronan Point incident, and some references in building codes, little was known about progressive collapse at that time. This was a blessing in disguise, however, because my colleagues and I at J. Muller International, San Diego, were free to develop our views and approaches almost from scratch. I have remained involved with this topic ever since. When entering academia a few years later, I had the time to reflect on the previous project-related work and to develop it further into a more formalised and generally applicable concept.

Progressive collapse is arguably the most dramatic and feared form of failure in structural engineering. It usually occurs unexpectedly and causes high losses. Although there has been an awareness for a long time that such failures can occur, this has barely been reflected, until recently, in a professional effort commensurate to the problem. Since the bombing of the Alfred P. Murrah Federal Building in 1995, and even more so since the events of 11 September 2001, research on progressive collapse has clearly intensified. Nevertheless, most publications only focus on particular aspects of the problem, and there is still no generally accepted use of nomenclature and procedures. The standard provisions that exist today lack general applicability.

This book attempts to close that gap. Its purpose is to give a plain and comprehensive introduction to the phenomenon of progressive collapse, to offer a consistent and generally applicable set of nomenclature and procedures, to provide guidance to the practicing engineer in both a systematic and pragmatic manner, and to give an outlook on future developments. Because the book is self-contained and requires only a basic understanding of structural analysis and design, it is also suitable and, I hope, particularly educational for advanced undergraduate and graduate students.

The book is based on a previous contribution to Betonkalender 2008, a yearbook popular among Germanspeaking structural engineers. Thanks are due to Konrad Bergmeister, the editor who had invited me to contribute, and to Ernst \& Sohn Verlag, Berlin, the publisher who has allowed the use of this previously published material.

Furthermore, I would like to gratefully mention a few individuals who helped shape my early understanding of the problem, namely Gerard Sauvageot, Jean Muller, 
Paul Mondorf, Daniel Tassin and Gamil Tadros. More recently, discussions with Robert Smilowitz, Mohammed Ettouney, Franco Bontempi and Luisa Giuliani have influenced my views in one way or another, which is also appreciated.

Special thanks are extended to Hyun-Moo Koh, my host at Seoul National University. During my sabbatical stay there, the collapse typology presented in this book came into being. Warm thanks are also due to his graduate student Yong-Suk Park for our discussions on bridge collapses.

I would like to thank my students at Hamburg University of Technology, most notably Maren Wolff and Marco Haberland, who were involved in some of the studies reported here. Moreover, they have read various parts and versions of the manuscript and helped to improve its clarity and correctness. The latter also applies to my brother Bernd Starossek. Thanks are also due to Deima Aslan and Todd Parry for helping with preliminary translations of some parts of the book, and to Axel Seils for preparing most of the illustrations.

Finally, it is a great pleasure to acknowledge my indebtedness to the one person without whom this project would not have been realised. Stuart Alexander encouraged me to submit the proposal for this book to Thomas Telford Ltd, and was instrumental in getting it accepted and bringing it to print. He reviewed the entire manuscript, and not only helped straighten out my English but also made many invaluable and helpful comments on the contents. Any remaining errors or misconceptions are my own.

Wholehearted thanks go to my wife Misuk and our children for their patience during the work on this book.

Uwe Starossek 


\section{About the author}

Uwe Starossek is a professor of structural engineering and head of the Structural Analysis Institute at Hamburg University of Technology in Germany. Moreover, he is a practitioner licensed as a professional engineer in California and as a checking engineer in Germany. His research on topics such as robustness of structures, progressive collapse, structural dynamics and vibration control has led to over 150 publications. The major projects Uwe has been involved with throughout his career have spanned continents and taken him to Brazil, the USA and Korea, among others. Uwe is a member of the ASCE SEI Disproportionate Collapse Technical Committee and Standards Committee, and a member of the Post-Tensioning Institute Committee on Cable-Stayed Bridges. 
Downloaded by [] on [26/04/23]. Copyright @ ICE Publishing, all rights reserved. 